\title{
EL TESTIMONIO \\ MUSICAL DE LOS \\ CRONISTAS DEL SIGLO XVI
}

Alejandro Mora Bustillo*

Aún más imperfecta que su poesía era su música. No tenían instrumento alguno de cuerdas; toda su música se reducía al huéhuetl, al teponaztli, a bocinas, a caracoles marinos y a ciertas flautillas que más servían para silbar que para otra cosa. [...]

Al son de estos dos instrumentos [huéhuetl y teponaztli] ... entonaban los mexicanos sus cánticos; el canto era duro y molesto a los oídos europeos, pero ellos percibirían tanto placer, que pasaban a veces en sus fiestas cantando todo el día. ${ }^{1}$

$\mathrm{E}_{1 \text { texto anterior, tomado de la Histo- }}$

ria Antigua de México de Francisco Javier Clavijero, nos muestra a la música prehispánica como una música bastante pobre y limitada. Resulta interesante la observación de Clavijero en el sentido de que la misma música que podía parecer molesta a los oídos europeos podía redundar en un gran placer para los indígenas. Es evidente que la música, como tantas otras cosas que los europeos encontraron a su llegada a América, debió resultar sorprendente y desconcertante, alejada de la realidad de los conquistadores, por su enorme diferencia con todo lo que conocían. Sin embargo, no todas las opiniones de los cronistas del siglo XVI muestran un juicio tan severo como el que mucho tiempo

\footnotetext{
* Licenciado en música, UNAM. Músico de la Orquesta de Guitarras de Jalapa.

${ }^{1}$ Francisco Javier Clavijero, Historia Antigua de México, 2003, México, Porrúa, p. 342-3.
} 
después, a finales del XVIII, emitirá Clavijero. Comparemos con la opinión de Francisco López de Gómara:

Estos dos atabales [teponaztli y huehuetl] concertados con voces, aunque allá no las hay buenas, suenan mucho, y no mal. Cantan cantares alegres, regocijados, y graciosos, o algún romance en loor de sus reyes pasados, recontando en ellos guerras, victorias, hazañas y cosas tales, y esto va todo en copla por sus consonantes que suenan bien y placen. ${ }^{2}$

¿De dónde vienen las diferencias de los juicios que sobre la música indígena emiten los cronistas? Para descubrirlo es necesario cotejar sus opiniones sobre la música prehispánica. Mucho más interesante sería poder cotejar, además, estas opiniones con la obra de arte que las suscitó, poder confrontar la reacción producida en el espectador europeo por una obra de arte de una cultura totalmente ajena a él. Esto, sin embargo, resulta imposible.

Dice Borges en El Hacedor: "En el tiempo hubo un día que apagó los últimos ojos que vieron a Cristo; la batalla de Junín y el amor de Helena murieron con la muerte de un hombre." Del mismo modo, la música indígena prehispánica se halla irremediablemente perdida: murió siglos atrás con el último hombre que la escuchó. Los testimonios escritos que nos quedan de quienes algún día la escucharon, de los cronistas que desde los oídos musicales de la Europa renacentista se enfrentaron a ella, así como a unos cuantos instrumentos, a las representaciones de músicos en el arte prehispánico y a los lejanos descendientes mestizos de aquella música, nos proporcionan algún indicio de cómo era, pero no podrán jamás reemplazar a la música en sí. Puede ser de cualquier manera un rico ejercicio el comparar las diversas reacciones estéticas de los europeos ante la música indígena de México.

Antes de seguir adelante en esta dirección, es importante mencionar, así sea de manera somera, cómo fue la reacción en el sentido

${ }^{2}$ Citado en Enrique Martínez Miura, La Música Precolombina, 2004, Barcelona, Paidós, p. 42. 
opuesto, es decir, cómo reaccionaron los indígenas ante la música europea. Para las culturas mesoamericanas, para las que la música y la danza constituían un elemento central del culto religioso y de la existencia misma, la música europea fue un elemento fascinante y cautivador, tal vez uno de los que más poderosamente hayan llamado su atención en el encuentro con el nuevo mundo que los conquistadores traían con ellos. Cuando los evangelizadores percibieron esto, convirtieron a la música en una de las armas más poderosas para atraer a los indígenas a la nueva religión. Fray Juan de Zumárraga en una carta de abril de 1540 al emperador Carlos V reconoce que los indígenas "más que por las predicaciones se convierten por la música, y los vemos venir de partes remotas para oírla y trabajan por aprenderla y salen con ello". 3

Tal vez el primero en aprovechar al máximo este hecho fue fray Pedro de Gante, quien en una carta a Felipe II dice, en 1558:

Por la gracia de Dios empecélos a conocer y entender sus condiciones y quilates, y cómo me había de haber con ellos. Toda su adoración de ellos a sus dioses era cantar y bailar delante de ellos. Siempre, antes que una víctima fuera sacrificada, habían de cantar delante del ídolo; y como yo vi esto, y que todos sus cantares eran dedicados a sus dioses, compuse metros muy solemnes sobre la ley de Dios y de la Fe; y enseñé en ellos cómo Dios se hizo hombre para salvar al linaje humano, y cómo nació de la Virgen María, quedando ella pura y sin mácula. ${ }^{4}$

Lo hecho por fray Pedro consistió en eliminar el texto de los cantares prehispánicos, sustituyéndolo por un texto cristiano. Las historias santas fueron traducidas por "los frailes en su lengua y los maestros de sus cantares las han puesto a su modo en metro que cuadre y se cante al son de sus cantares antiguos". 5

Pero volvamos al tema que nos ocupa. Es muy importante recalcar, aunque sea una verdad de perogrullo, que antes de poder entender la

${ }^{3}$ En Martínez Miura, op. cit., p. 244.

${ }^{4}$ Ibidem, p. 245.

${ }^{5}$ Motolinía citado por Gruzinski, El Pensamiento Mestizo, 2000, Barcelona, Paidós, p. 301. 
opinión de algún cronista sobre la música prehispánica, es necesario tomar en consideración una gran cantidad de factores, algunos muy evidentes, otros más sutiles. Así por ejemplo, es importante conocer el grado de cultura musical de quien escribe: ¿poseía una formación musical formal, era un músico popular o bien no tenía ningún conocimiento musical? Nos ayudará a entender muchas de sus reacciones también el conocer las circunstancias en que conoció la música indígena: no es lo mismo conocerla como uno más de los elementos de una batalla, como Bernal Díaz del Castillo, que haberla conocido transformada en elemento del culto religioso católico:

Digamos agora lo que los mejicanos hacían de noche en sus grandes y altos cues, y es que tañían el maldito atambor, que digo otra vez que era el más maldito sonido y más triste que se podía inventar, y sonaba lejos tierras, y tañían otros peores instrumentos y cosas diabólicas, y tenían grandes lumbres, y daban grandísimos gritos e silbos; y en aquel instante estaban sacrificando nuestros compañeros. ${ }^{6}$

Cuando esa música se convertía en presagio de una cercana muerte, difícilmente podía resultar en un goce estético.

Las reacciones de los cronistas ante la música son también influidas por el grado de simpatía o antipatía que de manera general les despiertan las culturas indígenas. En general, podríamos señalar que quienes repudian la música indígena, suelen describirla con atributos como triste, melancólica, dolorosa, lastimera, funesta, fría, poco suave. Por su parte, quienes son capaces de encontrar en ella algún tipo de placer estético, suelen señalar que existían tanto sones tristes como alegres, graciosos y regocijados.

Otro aspecto que debe tomarse en cuenta para comprender al máximo los testimonios musicales de los cronistas, es conocer la realidad musical de la que cada uno provenía. Tomemos en cuenta que hacia finales del siglo XVI la música europea se halla en un momento

${ }^{6}$ Bernal Díaz del Castillo, Historia Verdadera de la Conquista de la Nueva España, 1968, Madrid, Espasa Calpe, p. 376. 
de transición, un momento que culminará con el surgimiento de la música barroca. A la distancia, no es difícil pensar que este tipo de cambios se dan de manera suave y que ocurren más o menos de un día para otro. Esta ilusión es fácilmente estimulada por la necesidad de establecer algunos puntos de referencia. Pensemos, por ejemplo, en cómo muchísimas historias de la música señalan como final del barroco musical el año de la muerte de Juan Sebastián Bach, 1750. Por supuesto, esto no es más que una convención y una fecha que se toma como un punto de referencia, pero decir esto no supone que el primero de enero de 1751 los músicos europeos se hayan levantado sintiéndose clásicos, a diferencia de la noche anterior, en que se sentían barrocos. En la realidad este tipo de cambios ocurren tras un período en que las ideas nuevas y las viejas coexisten, en que los partidarios de nuevas ideas estéticas se enfrentan a los defensores del orden anterior.

La disquisición anterior es toda para señalar que, además de tomar en cuenta la época que un cronista está escribiendo, es necesario considerar su posición personal en torno a las polémicas musicales que se estaban dando en la Europa del siglo XVI. Muchas de las reacciones de los cronistas frente a la música indígena pueden servirnos, no sólo como una herramienta para conocer la música prehispánica, sino también como una forma de seguir el pensamiento musical europeo. Cuando el mismo objeto se ve reflejado de distintas maneras en espejos distintos, podemos averiguar más sobre los espejos que sobre el objeto reflejado. Dice fray Juan de Torquemada en su Monarquía Indiana:

Servíase siempre con mucha música de flautas, zampoñas, caracoles, huesos, atabales y otros instrumentos de poco deleite a los oídos de los españoles, y no alcanzaban otros mejores, ni tenían música de canto (como la que usamos en voces concertadas) porque no sabían el arte, hasta que de los castellanos lo aprendieron. ${ }^{7}$

En palabras de Torquemada la ausencia de la polifonía aparece como una de las grandes carencias de la música indígena, de la

${ }^{7}$ En Martínez Miura, op. cit., p. 89. 
música en voces concertadas. ¿Qué hubiera pensado en cambio un contemporáneo suyo como Vincenzo Galilei o cualquier otro de los defensores de la melodía acompañada que integraban la Camerata Fiorentina, quienes insistían en el absurdo de la polifonía para la clara comprensión del texto y las emociones de que era portador? Sin duda su opinión hubiera sido formulada en términos distintos y la ausencia de polifonía no se hubiera constituido en un elemento negativo, ya que el canto a una sola voz acompañada se identificaba para estos teóricos y músicos italianos con la música de la Grecia clásica.

De hecho, para un autor como el musicólogo español Faustino Núñez, es la presencia de América la que causará los cambios que llevan a la monodia y la tonalidad barrocas en Europa.

Por su parte, Fray Gerónimo de Mendieta cuenta:

Queriendo comenzar á bailar, tres ó cuatro indios levantan unos silbos muy vivos, luego tocan los atabales en tono bajo, y poco á poco van sonando mas. Y oyendo la gente bailadora que los atabales comienzan, por el tono de ellos entiende el cantar y el baile, y luego lo comienzan. Los primeros cantos van en tono bajo, como bemolados, y despacio, y el primero es conforme á la fiesta, y siempre le comienzan aquellos dos maestros, y luego todo el coro lo prosigue juntamente con el baile. ${ }^{8}$

Los primeros eran cantos 'en tono bajo, como bemolados, y despacio’. ¿Qué quiere decir esto? El libro de Mendieta fue escrito alrededor de 1595, como señala él mismo en el capítulo XX del cuarto libro. Un libro contemporáneo, la Guitarra española de Joan Carles Amat, de 1596, explica con todo detalle un sistema para escribir todos los acordes mayores y menores para su ejecución en la guitarra barroca o guitarra española. Allí, a los acordes mayores se les llama 'acordes naturales' y a los menores, 'acordes bemolados'. ${ }^{9}$ Es decir, Mendieta se refiere

${ }^{8}$ Fray Gerónimo de Mendieta, Historia Eclesiástica Indiana, 2002, México, CONACULTA, t. I, p. 264-5. Cursivas mías.

${ }^{9}$ Puede verse al respecto Eloy Cruz, La casa de los once muertos. Historia y repertorio de la guitarra, 1993, México, UNAM, Escuela Nacional de Música, p. 88-9. 
a que los primeros cantos tendrían algo que recuerda el modo menor de la música europea, lo que nos indica que está escribiendo ya desde una perspectiva musical que se basa en la división fundamental entre los modos mayor y menor, que se han afirmado ya como base del sistema musical europeo. Es interesante también la relación planteada entre el modo menor, el tono bajo y la lentitud. Mendieta continúa, un poco más adelante, en el mismo capítulo:

Acabado un cantar (dado caso que los primeros parecen mas largos por ir mas despacio, aunque todos no duran mas de una hora), apenas el atabal muda el tono, cuando todos dejan de cantar, y hechos ciertos compases de intervalo (en el canto mas no en el baile), luego los maestros comienzan otro cantar un poco mas alto y el compas mas vivo, y así van subiendo los cantos y mudando los tonos y sonadas, como quien de una baja muda y pasa á una alta, y de una danza en un contrapas. ${ }^{10}$

Sobre este contrapás del que habla Mendieta, algo nos puede decir Cervantes en sus Novelas Ejemplares. En efecto, en La Ilustre Fregona, asistimos a un baile a la puerta de una posada, "de muchos mozos de mulas que en ella y en las convecinas había”. La música corre a cargo de uno de los protagonistas, el Asturiano, que tocaba la guitarra de tal manera 'que decían que la hacía hablar'. Durante su canto improvisado, en un momento dice:

...con mudanzas y meneos

den principio a un contrapás.

Todo lo que iba cantando el Asturiano hicieron al pie de la letra ellos y ellas; mas cuando llegó a decir que diesen principio a un contrapás, respondió Barrabás, que así le llamaban por mal nombre al bailarín mozo de mulas:

${ }^{10}$ Mendieta, op. cit., p. 265. 
-Hermano músico, mire lo que canta, y no moteje a nadie de mal vestido, porque aquí no hay naide con trapos, y cada uno se viste como Dios le ayuda.

El huésped, que oyó la ignorancia del mozo, le dijo:

-Hermano mozo, contrapás es un baile extranjero, y no motejo de mal vestidos.

-Si eso es -replico el mozo-, no hay para que nos metan en dibujos; toquen sus zarabandas, chaconas y folías al uso, y escudillen como quisieren, que aquí hay personas que les sabrán llenar las medidas hasta el gollete. ${ }^{11}$

Es posible, entonces, leer los testimonios que nos han dejado los cronistas sobre la música indígena en busca de sus reacciones estéticas ante esa nueva realidad sonora. Claro que una lectura de este tipo no es de ninguna manera frecuente. Se inscribiría en el marco de una necesaria, aunque todavía irrealizada, historia de la música desde el punto de vista del oyente. Casi todas las historias de la música son de hecho historias de la composición musical, historias de los compositores y de la evolución de los estilos composicionales. En años más recientes, el interés por las prácticas de ejecución de cada época ha llevado a la producción de abundante bibliografía sobre la historia de la interpretación, de las prácticas interpretativas, pero aún está pendiente una historia de la parte final del proceso musical, la recepción por el oyente. ¿Qué buscaba en una obra musical un oyente medieval, qué lo hacía determinar si un intérprete era bueno o no? ¿Era lo mismo que buscaba un oyente barroco o lo que busca un escucha moderno? Las respuestas están todavía pendientes.

${ }^{11}$ Miguel de Cervantes, Novelas Ejemplares, 1983, México, Porrúa, p. 203. 